\title{
PEMBELAJARAN BERKOMUNIKASI SECARA MANDIRI MENGGUNAKAN APLIKASI INDOTTAVS SISWA TUNA RUNGU WICARA PADA SLB WIDYA BHAKTI DAN SLB SWADAYA SEMARANG
}

\author{
${ }^{1}$ Muljono, ${ }^{2}$ R. Arief Nugroho, ${ }^{3}$ Pujiono, ${ }^{4}$ Septian E. Sukmana, ${ }^{5}$ Syaiful A. Septemuryantoro \\ ${ }^{1,3,4}$ Fakultas Ilmu Komputer, Universitas Dian Nuswantoro \\ ${ }^{2,5}$ Fakultas Ilmu Budaya, Universitas Dian Nuswantoro \\ J1. Imam Bonjol 207, Semarang 50131 Telp. (024) 3517261, Faks. (024)3569684 \\ Email: ${ }^{1}$ muljono@dsn.dinus.ac.id, ${ }^{2}$ arief.nugroho@dsn.dinus.ac.id, ${ }^{3}$ pujiono@dsn.dinus.ac.id, \\ ${ }^{4}$ septian.enggar@dsn.dinus.ac.id, syaiful.ade@dsn.dinus.ac.id
}

\begin{abstract}
Abstrak
Salah satu permasalahan yang dihadapi Sekolah Luar Biasa (SLB) yang ada di kota Semarang adalah sangat sedikitnya jumlah SLB yang menangani siswa tuna rungu dan sangat terbatasnya jumlah guru khusus untuk melatih berkomunikas bagi siswa berkebutuhan khusus tuna rungu. Dengan adanya ketidakseimbangan rasio guru dan siswa, dimana jumlah guru sangatlah sedikit dibanding dengan jumlah siswa berkebutuhan khusus tuna rungu, maka banyak siswa tidak dapat tertangani secara rutin dan berkelanjutan dalam belajar dan berlatih berkomunikasi menggunakan bahasa Indonesia. Selain hal tersebut, kegiatan melatih berkomunikasi membutuhkan waktu yang lama dan berkelanjutan, sehingga banyak guru dan siswa yang jenuh dan bosan dalam kegiatan tersebut. Perguruan Tinggi (PT) adalah salah satu lembaga yang diharapkan berperan aktif dalam proses terlaksananya transfer ilmu pengetahuan atau knowledge transfer kepada masyarakat luas dalam bentuk diseminasi hasil penelitian yang telah dilakukan. Pelatihan pembelajaran mandiri berkomunikasi untuk siswa tuna rungu menggunakan sistem aplikasi Text To Audio Visual Speech Bahasa Indonesia (IndoTTAVS) yang telah penulis kembangkan, bertujuan untuk mengatasi permasalahan terbatasnya jumlah SLB dan guru yang menangani siswa tuna rungu, mengatasi kejenuhan dan kebosanan dalam proses belajar mengajar serta mempercepat kemampuan berkomunikasi bagi siswa tersebut. Aplikasi IndoTTAVS adalah sebuah aplikasi yang dapat membangkitkan suara dengan visualisasi (audio-visual) dari text yang dimasukkan. Visualisasi yang dibangkitkan dari text masukan, berupa sebuah animasi dari bentuk mulut yang terdiri dari bibir, gigi dan lidah yang akan bergerak sesuai dengan suara yang dihasilkan. Siswa dapat belajar berkomunikasi dengan cara menirukan gerakan mulut (bibir, gigi dan lidah) untuk berlatih bicara sesuai text yang diinputkan. Pelatihan sudah dilakukan di SLB B Swadaya dan SLB B Widya Bhakti Semarang. Siswa berlatih untuk memahami apa yang diucapkan dengan membaca gerakan mulut bibir (lip-reading) dari aplikasi dan berlatih menirukannya. Sistem ini dapat digunakan secara mandiri oleh siswa dan dapat digunakan oleh guru sebagai alat bantu pembelajaran dalam kelas.
\end{abstract}

Keywords: Bahasa Indonesia, Knowledge Transfer, Text To Audio Visual Speech, Tuna Rungu Wicara, Sekolah Luar Biasa 


\section{PENDAHULUAN}

Dampak kelainan pendengaran pada anak akan memberikan konsekuensi sangat kompleks, terutama berkaitan dengan masalah kejiwaannya. Pada diri penderita seringkali dihinggapi rasa keguncangan sebagai akibat tidak mampu mengontrol lingkungannya. Kondisi ini semakin tidak menguntungkan bagi penderita tuna rungu wicara yang harus berjuang dalam meniti tugas perkembangannya. Disebabkan rentetan yang muncul akibat gangguan pendengaran ini, penderita akan mengalami berbagai hambatan dalam meniti perkembangannya, terutama pada aspek bahasa, kecerdasan, dan penyesuaian sosial. Oleh karena itu, untuk mengembangkan potensi anak tuna rungu wicara secara optimal praktis memerlukan layanan dan bantuan secara khusus (Efendi, 2006; Tarigan, 1985).

Sebagaimana diketahui, peranan bahasa, bicara, pendengaran dalam konteks komunikasi kehidupan sehari-hari merupakan tiga serangkai potensi manusia yang mampu menjembatani proses komunikasi, sebab ketiga unsur tersebut dalam proses komunikasi masing-masing dapat menjadi pengontrol efektif dan tidaknya sebuah komunikasi. Oleh sebab itu, kepincangan salah satu komponen komunikasi tersebut berarti kehilangan kontributor besar yang dapat membantu manusia dalam meniti fase-fase tugas perkembangannya (Efendi, 2006).

Dari data Survey Sosial Ekonomi Nasional (SUSENAS) 2009 terdapat 223.655 orang tuna rungu, 151.371 orang tuna wicara dan 73.560 orang tuna rungu wicara (Kemensos RI, 2011). Di kota Semarang sendiri jumlah tuna rungu wicara semakin lama jumlahnya semakin meningkat. Jumlah tuna rungu wicara di kota Semarang tahun 2012 adalah 527 anak, meningkat pesat dari tahun-tahun sebelumnya. Dari sekian banyak banyak SLB yang ada kota Semarang, hanya ada 2 (dua) SLB yang menangani khusus tuna rungu wicara yaitu SLB B Widya Bhakti dan SLB B Swadaya. Jumlah guru yang ahli dalam menangani anak tuna rungu wicara sangat terbatas sehingga banyak siswa tidak dapat tertangani secara rutin dan berkelanjutan dalam belajar dan berlatih berkomunikasi.

Permasalahan yang dihadapi SLB B Widya Bhakti Semarang dan SLB B Swadaya Semarang adalah :

1. Bagaimana sekolah dapat melaksanakan proses pembelajaran berkomunikasi dengan lancar dan berkelanjutan bagi siswa tuna rungu wicara dengan jumlah guru dan fasilitas yang terbatas.

2. Bagaimana cara mengurangi rasa jenuh dan bosan bagi siswa dan guru dalam proses pembelajaran berkomunikasi tersebut, karena selama ini kegiatan pembelajaran tersebut membutuhkan waktu yang lama dan berkelanjutan.

Solusi yang diusulkan dengan melakukan pelatihan pembelajaran mandiri berkomunikasi untuk siswa tuna rungu wicara menggunakan aplikasi IndoTTS (_ Muljono et al., 2016; M. Muljono et al., 2016) yang telah dikembangkan penulis. Sistem ini digunakan sebagai alat bantu belajar berkomunikasi menggunakan bahasa Indonesia bagi siswa tuna rungu-wicara. Siswa dapat menirukan gerakan mulut (bibir, gigi dan lidah) untuk berlatih bicara sesuai text yang diinputkan. Siswa juga dapat berlatih untuk memahami apa yang diucapkan dengan membaca gerakan mulut bibir (lip-reading) dari aplikasi. Penggunaan sistem ini sangat mudah dan dapat digunakan secara mandiri oleh siswa dan dapat juga digunakan oleh guru sebagai alat bantu pembelajaran dalam kelas. Dengan memanfaatkan sistem ini, diharapkan dapat memberikan variasi dalam belajar, mengurangi kebosanan dan mempercepat kemampuan siswa dalam berkomunikasi(Agus, 2008; Harjanti, 2012; Nurhadi, 2005; Samsu, 2011; Zainul, 2007).

Penulis melakukan pelatihan dan pendampingan bagi guru dan siswa SLB B Widya Bhakti Semarang dan SLB B Swadaya Semarang dalam menggunakan sistem tersebut untuk pembelajaran berkomunikasi bagi siswa tuna rungu wicara sehingga guru dan siswa dapat menggunakan sistem tersebut secara mandiri 


\section{METODE PENELITIAN}

Dalam mengatasi permasalahan-permasalahan yang menjadi prioritas utama yang harus ditangani dalam kegiatan ini, maka pelaksanaan dan metode yang digunakan adalah sebagai berikut:

1. Identifikasi Permasalahan

Penulis telah melakukan identifikasi terhadap permasalahan-permasalahan yang terjadi dalam proses pembelajaran berkomunikasi bagi siswa tuna rungu wicara dan kendala kendala apa yang dihadapi guru dan siswa dalam kegiatan pembelajaran berkomunikasi selama ini, mendefinisikan dan mengkaji gambaran pelatihan pembelajaran berkomunikasi menggunakan sistem aplikasi "IndoTTAVS" secara keseluruhan, yang meliputi sarana, prasarana yang dibutuhkan, jadwal pelaksanaan kegiatan serta tujuan dan manfaat kegiatan pelatihan tersebut dan menetapkan metode analisis untuk eksplorasi dan evaluasi yang digunakan pada pelatihan ini dengan melakukan brainstorming dengan melibatkan pihak-pihak dalam kompetensi yang lebih luas, termasuk individu diluar pelaksana.

2. Proses Pelaksanaan Pelatihan

Pada tahap proses pelaksanaan pelatihan dilakukan proses pembelajaran, transfer ilmu pengetahuan dan pelatihan berkomunikasi bagi siswa tuna rungu wicara dan guru. Tujuan dari tahap ini adalah melatih guru dan siswa agar mahir menggunakan sistem aplikasi dan siswa dapat memanfaatkan sistem aplikasi ini untuk belajar berkomunikasi secara mandiri diluar jam belajar kelas. Pelaksanaan pelatihan ini diikuti oleh maksimal 30 peserta. Pelatihan diadakan di 2 lokasi, yaitu di SLB B Widya Bhakti Semarang dan SLB B SWADAYA Semarang.

3. Evaluasi, Monitoring dan Pendampingan

Dalam tahap ini dilakukan evaluasi, pemantauan secara periodik dan pendampingan yang simultan terhadap kegiatan pelatihan pembelajaran berkomunikasi bagi siswa tuna rungu wicara. Evaluasi dilakukan terhadap kinerja dari sistem aplikasi tersebut dengan menggunakan pengukuran subyektif. Pengukuran subyektif terhadap kinerja sistem aplikasi dilakukan menggunakan metode Mean Opinion Score (MOS) yaitu suatu metode mencari nilai rata-rata pendapat dari responden yang terlibat dalam pelatihan.

\section{HASIL DAN PEMBAHASAN}

Aplikasi IndoTTAVS yang telah dikembangkan penulis untuk pelatihan berkomunikasi secara mandiri bagi siswa tuna rungu wicara di SLB B Swadaya dan SLB B Widya Bhakti adalah aplikasi berbasis web dan dijalankan menggunakan web browser. Aplikasi ini dikembangkan menggunakan bahasa pemrograman PHP.

Untuk menjalankan aplikasi ini, Buka web browser pada komputer, kemudian ketikan alamat localhost://ittvs-lip/, kemudian tekan enter. Akan muncul tampilan menu utama dari sistem aplikasi tersebut seperti pada gambar 1. 


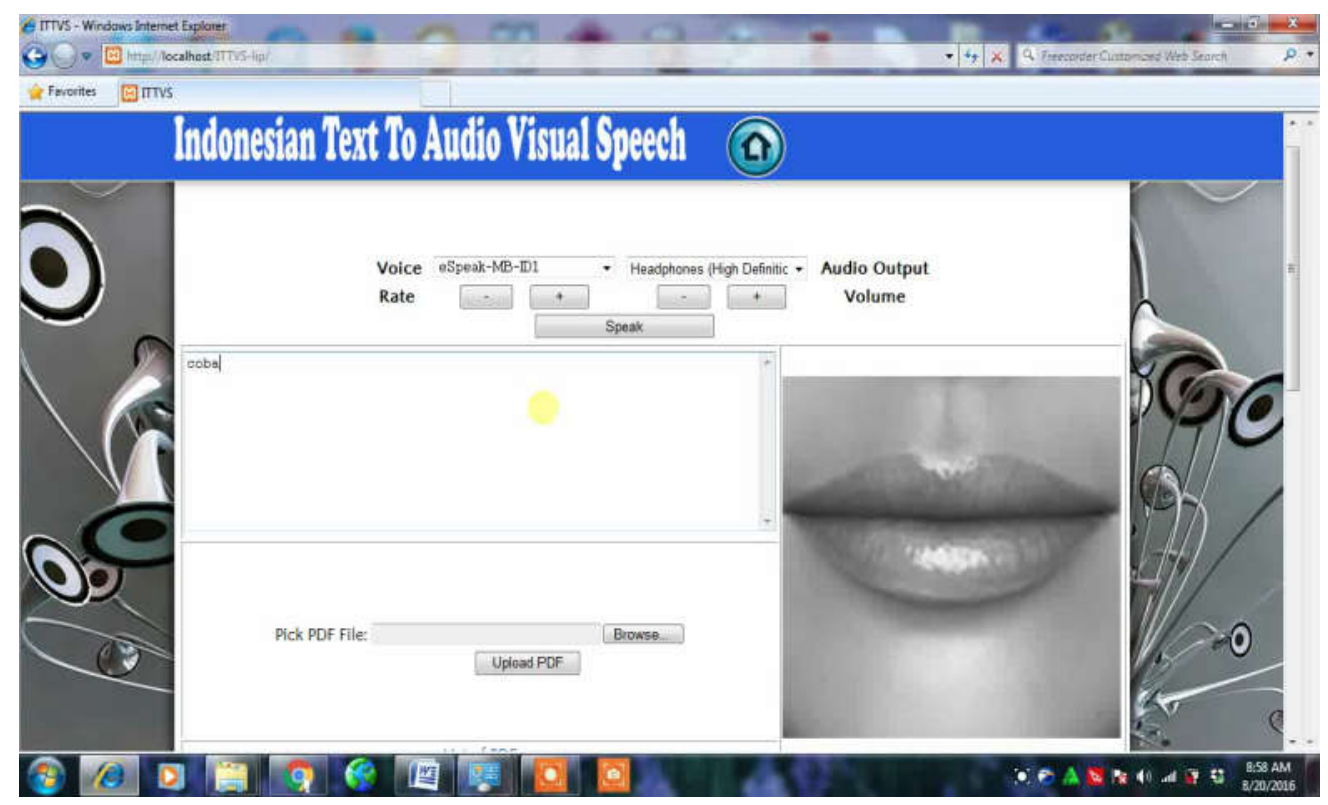

Gambar 1. Desain Menu Utama Aplikasi "IndoTTAVS"

Setelah menu utama dari sistem aplikasi muncul, pengguna dapat mengetikkan teks di dalam "Text Box" atau mengunggah file pdf. Untuk mengunggah file pdf, pengguna dapat mencari file dari folder lokal dengan mengklik tombol "Browse", pilih dan klik tombol "Upload PDF". File Pdf akan otomatis dikonversi menjadi teks dan ditampilkan di dalam "Text Box". Pengguna kemudian mengeklik tombol "Speak" untuk mendengarkan ujaran/ucapan yang dihasilkan dari teks dan melihat visual ujaran yang dihasilkan yang divisualisasikan oleh animasi kepala berbicara (animated talking head). Ujaran dan visualisasi ujaran dihasilkan secara simultan berdasarkan masukan yang diberikan. Untuk menambah atau mengurangi tempo bicara, pengguna bisa mengklik tombol ' + ' atau '-' pada menu Rate. Untuk mengaktifkan atau mematikan volume, pengguna dapat mengklik tombol ' + ' atau '-' pada menu Volume. Pelaksanaan pelatihan dilakukan proses pembelajaran, transfer ilmu pengetahuan dan pelatihan berkomunikasi bagi siswa tuna rungu wicara dan guru. Tujuan dari tahap ini adalah melatih guru dan siswa agar mahir menggunakan sistem aplikasi dan siswa dapat memanfaatkan sistem aplikasi ini untuk belajar berkomunikasi secara mandiri diluar jam belajar kelas. Total peserta yang mengikuti pelatihan ini sebanyak 50 peserta terdiri dari 10 Guru dan 40 siswa. Pelatihan diadakan di 2 lokasi, yaitu di SLB B Widya Bhakti Semarang dan SLB B SWADAYA Semarang.

Dalam pelatihan tersebut penulis memperoleh beberapa masukan, diantaranya, Masukan pertama, tentang kesulitan siswa dalam belajar berkomunikasi dengan cara konvensional, diantarnya seperti :

1. Tidak mandiri, artinya Siswa tidak dapat berlatih secara mandiri, siswa terlalu bergantung pada guru.

2. Tidak kontekstual, artinya Siswa tidak dapat mempelajari konteks berkomunikasi yang dia mau. Semuanya tergantung pada pokok bahasan yang dipelajari guru.

3. Kurang menyenangkan, artinya Suasana belajar kurang menyenangkan, karena situasi belajar mengajar dalam situasi formal.

4. Tidak mendukung mobilitas, artinya Pada era sekarang, murid-murid penyandang tunarungu wicara membutuhkan sebuah media pembelajaran yang bersifat portable yang dapat membantu mereka melatih kemampuan berkomunikasi kapan dan di manapun juga.

Masukan kedua, observasi pembelajaran berkomunikasi menggunakan IndoTTAVS.

1. Disiplin murid, murid lebih mudah diatur ketika mereka menggunakan IndoTTAVS dibandingkan dengan menggunakan pembelajaran konvensional. Pada pembelajaran 
konvensional, murid kadang bertindak sesukanya sendiri. Dalam hal ini, teknologi berperan untuk membuat murid lebih fokus.

2. Variasi ujaran, murid banyak berlatih ke banyak unit linguistik (kata sampai kalimat) yang mereka kehendaki. Dengan demikian, ujaran yang mereka latih lebih variatif.

Masukan ketiga, tentang evaluasi terhadap sistem IndoTTAVS. Untuk mengevaluasi kelebihan dan kekurangan sistem, penulis menggunakan kuesioner kepada 10 guru dan

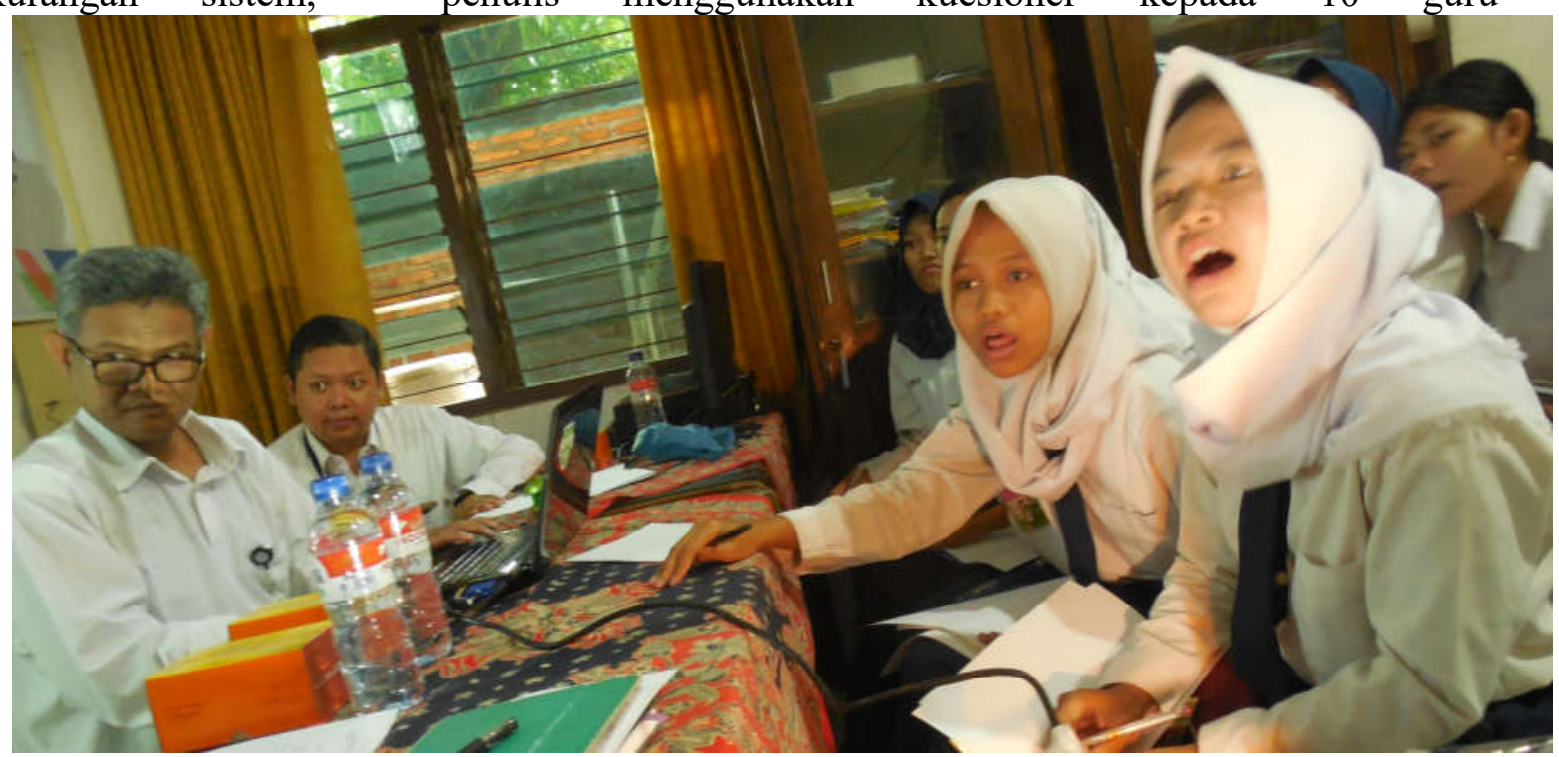

Gambar 2. Kegiatan Pelaksanaan Pelatihan Menggunakan IndoTTAVS di SLB Swadaya

40 siswa SLB. Kuesioner dibagikan saat proses pembelajaran berkomunikasi menggunakan sistem ini.

Dari 10 guru yang dibagikan kuesioner, semuanya setuju bahwa sistem IndoTTAVS membuat pembelajaran lebih fokus, dapat digunakan secara mobile, dan mudah dioperasikan. Sedangkan dari 10 guru, hanya 4 guru yang setuju bahwa IndoTTAVS dapat melatih berbagai variasi ujaran. 6 guru lain berpendapat bahwa IndoTTAVS masih kurang memiliki variasi ujaran karena keterbatasan visualisasi bibir.

Sedangkan dari 40 murid yang dibagikan kuesioner, semuanya setuju bahwa IndoTTAVS membuat pembelajaran lebih menyenangkan dan mudah dioperasikan. Sedangkan dari 40 murid, hanya 10 murid yang setuju bahwa IndoTTAVS dapat melatih mempelajari gerak bibir. 30 murid lainnya berpendapat bahwa IndoTTAVS memiliki keterbatasan visualisasi bibir. Keterbatasan tersebut sama dengan yang dikeluhkan oleh guru dalam kuesioner mereka.

Dari masukkan guru dan siswa yang ikut dalam pelatihan, ada beberapa kekurangan dari sistem IndoTTAVS ini, antara lain : tatar belakang IndoTTAVS tidak berwarna cerah, gerak bibir IndoTTAVS kurang bulat dan utuh, gerak bibir IndoTTAVS terlalu cepat menutup, warna bibir IndoTTAVS tidak berwarna cerah dan pengaturan tempo gerakan bibir belum maksimal.

\section{KESIMPULAN}

Dalam tulisan ini, pengabdi dapat menyimpulkan beberapa poin. Poin-poin tersebut terdapat dalam dua kategori, yaitu kategori pelaksanaan PKM dan kategori kebermanfaatan aplikasi. Di kategori pelaksanaan PKM, pengabdi dapat menyimpulkan bahwa program telah berhasil dilaksanakan di dua SLB-B di kota Semarang. Dua sekolah tersebut dipilih karena hanya kedua SLB tersebut yang memiliki siswa didik tunarungu-wicara di Semarang.

Pelaksanaan program ini disambut baik oleh jajaran Kepala Sekolah dan guru. Di program yang dilaksanakan tanggal 29 Agustus 2017 (SLB B Swadaya Semarang) dan 30 Agustus 2017 (SLB B Widya Bhakti Semarang) itu diikuti oleh semua guru dan siswa terpilih. Siswa dipilih berdasarkan kemampuan membaca bibir tingkat menengah dan minimal sudah SMP. 
Dari hasil kuesioner yang berhasil diedarkan setelah program selesai, pengabdi dapat menyimpulkan bahwa seluruh guru dan murid memiliki harapan tinggi agar aplikasi ini dapat dikembangkan dan diaplikasikan dalam pembelajaran. Mereka menganggap bahwa aplikasi ini menjadi satu-satunya aplikasi yang dapat membantu tunarungu-wicara berlatih membaca gerak bibir secara mandiri. Lebih lanjut, dari kuesioner, pengabdi dapat menyimpulkan bahwa kemampuan membaca gerak bibir yang baik sangat menunjang komunikasi tunarungu-wicara. Para guru dan murid sepakat bahwa hal tersebut merupakan satu-satunya cara memahami komunikasi dan berkomunikasi, karena mengajarkan masyarakat awam untuk menguasai bahasa isyarat jelas hal yang sangat sulit. Untuk itu, tunarungu-wicara diharapkan dapat membaca gerak bibir mitra wicara dan melatih bentuk bibir mereka agar ujaran mereka dapat dipahami oleh mitra wicaranya. Tujuan itulah yang sedang dirintis melalui terciptanya aplikasi ini.

\section{SARAN}

Melalui kuesioner yang diedarkan kepada guru dan murid setelah pelatihan PKM selesai, pengabdi mendapati beberapa saran untuk pengembangan aplikasi ini, antara lain:

a. Warna bibir hendaknya lebih mencolok

b. Pipi/wajah diperlihatkan

c. Lidah diperlihatkan

d. Tempo bentuk bibir lebih lambat

e. Bentuk bibir ketika bicara lebih bulat

\section{Ucapan Terima Kasih}

Terimakasih banyak penulis ucapkan kepada Kemeristekdikti atas dukungan dana pada Program Kemitraan Masyarakat (PKM) tahun 2017 dan SLB B Swadaya dan SLB B Widya Bhakti Semarang atas kerjasamanya sehingga kegiatan PKM ini bisa terselenggara dengan lancar dan sukses.

\section{DAFTAR PUSTAKA}

Agus, S., 2008. Manfaat Komputer Dalam Pembelajaran. Makalah Dalam Mata Kuliah Aplikasi Komputer dan Internet.

Efendi, M., 2006. Pengantar Psikopedagogik Anak Berkelainan. PT. Bumi Aksara Jakarta.

Harjanti, A., 2012. Korelasi Antara Kemampuan Membaca Pemahaman Dengan Prestasi Belajar IPS Siswa Kelas IV SD Negeri Se-Kecamatan Kokap Kabupaten Kulon Progo. Universitas Negeri Yogyakarta, Yogyakarta.

Kemensos RI, 2011. Pedoman Penjangkauan Rehabilitasi Sosial Penyandang Disabilitas Rungu Wicara di Masyarakat. Jakarta. Direktorat Rehabilitasi Sosial Orang dengan Kecacatan Jakarta.

Muljono, _, Sumpeno, S., Arifianto, D., Aikawa, K., Purnomo, M.H., 2016. Developing an Online Self-learning System of Indonesian Pronunciation for Foreign Learners. Int. J. Emerg. Technol. Learn. IJET 11, 83-89.

Muljono, M., Sumpeno, S., Arifin, A., Arifianto, D., Purnomo, M.H., 2016. Indonesian Text to Audio Visual Speech with Animated Talking Head. Int. Rev. Comput. Softw. IRECOS 11, 261-269.

Nurhadi, 2005. Bagaimana Meningkatkan Kemampuan Membaca? Sinar Baru Algesindo, Bandung. Samsu, S., 2011. Strategi dan Teknik Pembelajaran Membaca. Graha Ilmu, Yogyakarta.

Tarigan, H.G., 1985. Membaca sebagai Suatu Keterampilan Berbahasa. Angkasa, Bandung.

Zainul, M., 2007. Penggunaan Komputer dan Akses Internet Sebagai Pendukung dalam Aktifitas Belajar Tunanetra (Stadi Kasus Terhadap Siswa dan Mahasiswa Tunanetra Pengguna Komputer dan Internet di Yayasan Mitra Netra. UPI, Bandung. 